\title{
As linguas ameríndias e a Arte de Gramática-gramaticografia de Anchieta e Carochi até a Gramática Mexicana de Wilhelm von Humboldt
}

Werner Thielemann Universidade Humboldt de Berlim (Alemanha)

\section{Abstract}

The description of Amerindian languages is closely linked to the evangelization and catechesis of indigenous American peoples by religious orders (Franciscans, Jesuits and others). Grammaticography of native languages, since the discovery of America and for a long time, was being influenced by the translation practice of catechetical Latin texts and, in this way, from Ars grammaticae principles and terminology of Latin.

Though being aware of the particularities of indigenous languages, missionaries do not trangress the degree of descriptive 
hybridity, evidenced by the Brasilian Grammar of Anchieta and a lot of Mexican nabuatl grammars (Olmos, Carochi), discussed in the article.

Paradigmatic change arises with Historical Comparative Grammar in Europe. The description of American languages changes totally, when, whit his knowledge of Basque, Whilhelm von Humboldt recognizes the propositional value of the nabuatl verb and identifies incorporation as the organizing principle. He initially gives an adequate description and metalinguistic teminology for the particularities of Amerindian languages. Throughout his life, he is tried to determine the structures of American languages, but the very results of his endeavour were not published until after his death (1835). 


\section{O ENCONTRO COM AS LÍNGUAS DOS ÍNDIOS NAS AMÉRICAS}

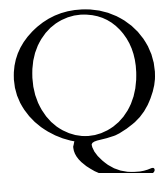

uando os primeiros europeus chegaram à América, constataram que, diferentemente dos países e regiões que descobriram na África ou na Ásia, estavam em contato com línguas que os intérpretes não dominavam. No caso do Brasil, Pêro Vaz de Caminha (?-1501), na sua relação ao Rei D. Manuel, diz o seguinte:

Estes Indios sam de côr baça, e cabello corredio; tem o rosto amassado, e algumas feições delle á maneira de Chins. [...]

A lingoa de que usam, toda pela costa, he huma: ainda que em certos vocabulos differe n'algumas partes; mas nam de maneira que se deixem huns aos outros de entender: e isto até altura de vinte e sete gràos, que dahi por diante ha outra gentilidade, de que nós nam temos tanta noticia, que falam já outra lingoa differente. Esta de que trato, que he ageral pela costa, he mui branda, e a qualquer nação facil de tomar. Alguns vocabulos ha nella de que nam usam senam as femeas, e outros que nam servem senam pera os machos [...]. ${ }^{1}$

Caminha já fala de língua geral: "Esta [língua] de que trato, que he a geral pela costa." Torna-se claro que o tupinambáé dialetalmente fragmentado, mas que as variações não impedem o entendimento: "ainda que em certos vocábulos differe n'algumas partes; mas nam de maneira que se deixem huns aos outros de entender." O que, ao contrário, se reconhece desde o início como particular é a diferenciação entre lingua de homens e "lingua de fêmeas".

Está fora de dúvida que, de modo decisivo, o que contribuiu para o conhecimento e ensino das línguas do Novo Mundo foi o fato de tanto espanhóis como portugueses terem visto, nesse Novo Mundo, um Continente que deveriam missionar, catequizar e conquistar para 
o império da Igreja Católica, única igreja ortodoxa. Cada fé diferente era heresia, isso sem falar dos "salvagens" da terra brasílica dos quais na Carta do Gândavo (1576) se diz:

[...] carece de tres letras, convem a saber, nam se acha nella $F$, nem $\mathrm{L}$, nem R, cousa digna despanto porque assi nam têm Fé, nem Lei, nem Rei, e desta maneira vivem desordenadamente sem terem alem disto conta, nem peso, nem medido. ${ }^{2}$

Assim, só é conseqüência se as Ordens - na continuação das Cruzadas - virem a sua missão na propagação da fé cristã no mundo inteiro, tal como, nos Sermões, o Pe. Antônio Vieira (1608-1697) a tematiza, utilizando várias imagens e comparações.

O alvo da evangelização se vê reforçado com a concorrência provocada pela Reforma na Alemanha, Inglaterra e França, no seguimento da qual os protestantes franceses, flamengos e também ingleses entraram em competição no Brasil com os missionários católicos.

No âmbito português, foram, antes de tudo, os Jesuítas (já a partir de $1549^{3}$ ), o Padre Nóbrega, ${ }_{4}^{4}$ os Padres Anchieta ${ }^{5}$ e Vieira que se tornaram verdadeiros defensores da idéia do Brasil como "Almazonas". 6 Agora, o alvo era assegurar o poder secular, por um lado, e a influência eclesiástica, por outro. As orientações são - sobretudo na América Espanhola ${ }^{7}$ - contraditórias. Para o poder secular, o Castelhano se tornou a lengua del Império, enquanto as Ordens de atividade evangélica (antes de tudo Franciscanos, Carmelitas, Augustinos e Jesuítas, os mais zelosos entre eles) ${ }^{8}$ defenderam a idéia de que a catequese devia ser feita na língua dos indígenas.

Os grandes esforços dos frades e padres para elaborar Artes de Gramática das línguas indígenas são bem notórios e foram suficientemente tematizados. Em 1547, aparece a Arte de Grammatica Mexicana de Andrés de Olmos e, a partir de 1555 (impressão: 1595), existe a Arte de Grammatica da Lingua mais falada na Terra Brasílica, redigida pelo Pe. José de Anchieta. Tudo isso cria condições fantásticas tanto para a evangelização dos índios, como para a transferência mútua de bens culturais. Tal constatação vale sobretudo para a Nueva España, México, onde os indígenas começaram a 
anotar a história de seus povos em latim, e onde essas histórias também foram impressas. A grande vantagem da Nueva España consiste no fato de a língua dos Maias ser de grande cultura, capaz de diferenciar vários registros (parcialmente também marcados nas Gramáticas). Entretanto, o perigo de influência do espanhol sobre as línguas indígenas não pode ser excluído. Humboldt, consciente disso, escreve no seu pedido a Alamán:?

Uma cópia precisa de mais ou menos uma dúzia de páginas de tal parte dos manuscritos da qual se poderá supor que o estilo é muito puro e pouco influenciado pelo conhecimento das gramáticas castelhana e latina que os autores dessas obras podem ter tido. ${ }^{10}$

\section{A GRAMÁTICA DE NEBRIJA}

São vários os aspectos em que o ano de 1492 é decisivo e simbólico para a Espanha, para a Península Ibérica e para o Novo Mundo. O ano de 1492 é conhecido, por um lado, como data do Descobrimento da América, mas, por outro, em Castela, é também o ano do fim da Reconquista, ano de vitória militar, em que Castela, finalmente, consegue conquistar Granada e vencer os Mouros; e, como terceiro ponto, o ano em que foi publicada a célebre Grammatica de la lengua castellana de Antônio Nebrija, em Salamanca.

A gramática de Nebrija tem não só valor intelectual, mas também é importantíssima para o poder e o prestígio da Coroa, fato provado pela citação seguinte, atribuída ao Bispo de Ávila.

[...] me arrebató la respuesta, y respondiendo por mí, dixo que despues que Vuestra Alteza metiesse debaxo su iugo muchos pueblos bárbaros y naciones de peregrinas lenguas, y con el vencimiento quelles tenían necesidad de recibir las leies que el vencedor pone al vencido, y con ellas nuestra lengua, entonces por esta mi Arte, podrían venir al conocimiento della. (QUILIS, 1989: 113)

A superioridade será tanto cultural como civilizatória e militar, mas sempre ligada ao poder. Assim, a Gramática e o domínio da língua ficam diretamente instrumentalizados pelo poder e são usados para 
abaixar, sujeitar e eliminar outras culturas, para suprimir e nivelar os povos nomeados bárbaros. A obra intelectual serve imediatamente às pretensões imperiais da Coroa de Castela. Não parece nada exagerado julgar isso como orgulho imperial e falta de compreensão e tolerância da diversidade cultural de outras etnias e nações. A política de Castela é a do castelhano "lengua del Imperio".

No entanto, o comportamento da Coroa Portuguesa é diferente. Portugal, país pequeno, e, nesta altura, com um milhão de habitantes (em 1532: 1,2 milhões), tem um conceito diferente da política dos Descobrimentos e da ocupação ou controle dos litorais em vastas partes do mundo. Portugal favorece a ligação e a mestiçagem com os indígenas e tal orientação se manifesta também em uma política lingüística marcadamente diversa.

Seguindo o modelo colonizador do Levante (modelo de fenícios e gregos), Portugal vai estabelecendo fortalezas para controlar e negociar com as populações do binterland, no caso da África e da Índia. Nas condições de uma população escassa como no Brasil, os moradores organizam saídas, bandeiras, para os territórios interioranos. Neste caso se estabelece uma língua franca, no Brasil, língua geral com os indígenas. A língua franca só em parte tem o cunho português (pidgins, crioulo).

Mas também em Portugal, na época do Humanismo, há Gramáticas do vulgo. Em 1536, aparece a Gramática de Fernão de Oliveira; em 1540, A Gramática da Lingua Portuguesa. Cartinha, Gramática, Diálogo em louvor da nossa linguagem e Diálogo da Viciosa Vergonha de João de Barros. A Gramática de João de Barros é expressão da consciência nacional dos portugueses, mas nunca será base de política "o Português - língua do Império", nem no Oriente, nem no Brasil.

Será só dois séculos mais tarde - com os Decretos lingüísticos do Marquês de Pombal - que o português haverá de ser imposto como língua vernácula na colônia do Brasil. O que, no entanto, se vai desenvolvendo paralelamente, são gramáticas das línguas vernáculas do Novo Mundo. Já em 1547 temos a primeira Gramática da Lengua Mexicana de Andrés de Olmos. 


\section{A GRELHA DO LATIM}

A descrição das línguas ameríndias segue não só de forma parcial, mas integral, o modelo canônico da Ars grammaticae, modelo metalingüístico do latim, isto é, as línguas são descritas como "espelho do latim".

Já no século XIX, dada a inteligência sempre mais detalhada de idiomas singulares, a história da gramaticografia começou a criticar o método de projeção sobre o latim. ${ }^{11}$ Assim, Wilhelm von Humboldt-muito longe de desvalorizar a obra dos Jesuítas de que várias vezes fala com grande estima ${ }^{12}$ - duvida que os missionários, para descrever as línguas do Novo Mundo, dispusessem de conhecimentos adequados.

Só que todos esses homens, aliás respeitáveis, foram pouco indicados para investigar línguas, cuja estrutura pouco comum lhes foi estranha. É triste ver que violência eles fizeram a si mesmos e às línguas para apertá-las nas regras estreitas da gramática latina de Antônio de Nebrija ou de outro pedante castelhano. Preencheram páginas inteiras com reflexões sobre a pergunta se esta ou aquela língua dispõe ou não de um Particípio ou de um Supino ou Gerúndio. (HUMBOLDT, 1994: 222 - tradução e grifo nosso.)

E assim foi! As críticas que Humboldt formulou caracterizam o mal pela raiz: a gramaticografia dos missionários vestiu um colete latino às línguas indígenas. Tal molde se explica tanto ideológica como lingüisticamente. $O$ verdadeiro rigor vem da religião e da ideologia. Os missionários têm como alvo evangelizar, impregnar os indígenas das doutrinas do Catolicismo para, e Humboldt tematiza isso, melhor exterminar as próprias culturas indígenas.

Mas, para os índios, o Evangelho é matéria desconhecida, ideário tão diferente que o "choque cultural" não pode deixar de se produzir. No entanto, e nisso consiste a estratégia dos Jesuítas, o ensino da doutrina se tornará mais eficaz, isto é, compreensível e atrativo, quando apresentado em língua local.

A descrição lingüística como tal não aproveita isso, antes pelo contrário. Por um lado, os missionários deviam se render à evidência 
de que as línguas ameríndias eram, do ponto de vista estrutural, fortemente diferentes do latim e respectivamente das línguas filhas do latim e que, assim sendo, eram incomensuráveis para as línguas européias. Por outro lado, os textos de catequese escritos em latim ou vulgar deviam ser traduzidos. Com o dogma da ortodoxia, a tradução, automaticamente, estava sujeita a constrangimentos extralingüísticos. Assim, foi mais ou menos conditio sine qua non rastrear sobre o latim os textos catequéticos redigidos em língua vernácula.

O empenho evangélico conduz a dois tipos de texto: textos catequéticos e sermões, por um lado; gramáticas e manuais pedagógicos, por outro. Nos textos catequéticos, a dignidade é o maior fator de influência latina, além do impacto estrutural da língua dos romanos que ressalta à vista. A dignidade é noção que, ao lado do conteúdo, contém também uma vertente lingüística e, sobretudo, estilística. A forma lingüistica devia corresponder ao caráter sagrado da Palavra de Deus. Não obstante tal influência latina, temos que sublinhar o caráter lingüisticamente híbrido dos escritos e obras dos padres.

\section{A ARTE DE GRAMMATICA DA LINGUA MAIS USADA NA COSTA DO BRASIL DO PE JOSEPH DE ANCHIETA}

Como já dito, o interesse dos portugueses pelas línguas indígenas é sensivelmente condicionado pela atividade da missão e, em especial, das missões jesuíticas.

Em 1549, os Jesuítas desembarcam pela primeira vez no Brasil, com o Padre Manuel de Nóbrega. Já em 1555, eles dispuseram da primeira gramática do tupinambá: Arte de Grammatica da lingoa mais usada na costa do Brasil do $\mathrm{P}^{\mathrm{e}}$ Joseph de Anchieta, impressa em Coimbra só em $1595 .{ }^{13}$ Anchieta conseguiu aprender rapidamente a língua dos naturais da terra e parece que a dominou a fundo. E este fato não é para se estranhar, visto que o princípio de Nóbrega foi fazer conviver os missionários com os índios, fazê-los viver nas suas aldeias. A Arte de Anchieta, funcionalmente, faz parte da área da catequese dos índios. 


\subsection{A descrição das línguas tupi sobre a grelha da língua latina}

A Gramática de Anchieta está baseada primordialmente no esquema canônico da Ars Grammaticae (espelho da língua latina), tal como usada em modelo metalingüístico para descrever o latim. Não obstante esta avaliação geral, as gramáticas revelam um certo grau de hibridez, fato que vale tanto pela doutrina quanto pela língua. A divergência entre as duas é mínima. Segundo tal orientação, o tupi, para todas as categorias gramaticais do latim, terá que disponibilizar equivalentes. Para dizê-lo de maneira moderna, o latim funciona como o tertium comparationis no qual a língua descrita terá que ser moldada.

Um dos tópicos centrais são os casos. As gramáticas vulgares da época, reforçadas pelo exemplo de Nebrija, pressupõem, alegre e despreocupadamente, a existência de casos nas línguas vulgares e ameríndias: "Los casos en el castellano son cinco: [...]" ${ }^{14}$ Hesitante, Anchieta segue o mestre castelhano, comparando, não obstante, com casos, inexistentes no tupi, para explicar as funções das partes de oração:

[...] têm em vista esclarecer quanto à função da palavra na oração, donde resulta que o termo nominativo serve para referir o sujeito ou $\mathrm{o}$ agente, enquanto $\mathrm{o}$ acusativo surge quando se quer falar da função de complemento directo ou de paciente, [...] (SOARES PEREIRA, 2001: 1343).

Os pronomes também se vêem dotados de casos:

(1) A mesma declinação tem este nome, Acê, ut: Nom. Acê. Dativo. Acébe, uel Acébo. [... ] Na construição quando he accusativo, praepoem se immediato ao verbo [...] (ANCHIETA, 1595: 12r).

Anchieta finge que todas as categorias do latim se deveriam reencontrar no tupi. Tal estratégia, motivada didaticamente, resulta do empenho de, com base nas categorias do latim, capacitar o missionário para traduzir o tupi. Veja-se o exemplo do gerúndio:

(2) Formação do Gerúndio in Do, vel Dum, ou supino

Os verbos acabados em vogal com acento na última acrescentam bo, como juká matar, jukábo matando. 
Os acabados em $y$ ou $u$ interpõem $a$, como aby faltar, abyábo faltando; $u$ comer, uábo ou guábo comendo; recorre à regra do $g$ interposto, como acima ficou dito [...] (ANCHIETA, 1595: 28v).

Para a gramática da língua, isso significa o seguinte: os equivalentes de gerúndios (latinos) encontrados no texto catequético (textofonte) se vêem reduzidos a regras da Arte do tupi; isto é, uma escolha pragmático-funcional de meios, reunidos na base de critérios funcionais, mas que, no nível da estrutura gramatical da língua, não correspondem em nada à estrutura genuína do idioma. Por outras palavras: o tupi, a partir da tradução catequética, se vê dotado de estruturas que são reflexos do latim.

Anchieta indica meios do tupi que possam se substituir significativa e estruturalmente ao gerúndio latino. $\mathrm{O}$ fato de, em seguida, no ensino do tupi, essas formas se "venderem" por gerúndio da língua geral parece, mesmo comparado à formulação de Anchieta, um maior grau de imprecisão e de conseqüências incalculáveis para a "gramática" do idioma. Com tudo isso, não se pode negar o empenho de Anchieta em familiarizar o aluno (futuro missionário) também com as finezas da língua, explicar-lhe a estrutura do tupi. ${ }^{15}$ Veja-se para o Nome:

(3) R.T. comunicãose infine, pondo t. pro, r. vt in præsenti exemplo, \& tambe nos verbos, vt aîur, aiût, mas na conjugação não se faz caso do, t. senão do, r.

O que dá muito nas vistas é a amálgama discursiva entre latim e vulgo: infine, in praesenti exemplo, ut, pro, ... Esta mistura de prática é destinada a pessoas que não sabem o latim ou incapazes de seguir o discurso metalingüístico nessa língua. Mas o autor decide conservar parte do discurso em latim. Deste modo, intensifica o caráter terminológio do discurso. Tais exemplos de discurso misto poderiam ser acumulados ad infinitum. São provas de modelação do idioma exótico, partindo da grelha do latim, destinado, portanto, a um público que ignora tal tradição ou só a conhece de maneira rudimentar. É por isso que a Ars Grammaticae, na maioria dos casos, 
usa o vulgo e não o latim como meio comunicativo. Um outro aspecto são as particularidades idiomáticas das línguas exóticas, fenômeno que fica registrado como desvio do canônico, obedecendo a norma ao modelo clássico. Veja-se:

(4) O plural se entende pello que se trata, ou tambem acrescentandolhe algus nomes, que significão multidão como, todos, tantos, quantos, muitos, \&. E este vltimo he vsado pera isto que he cetâ, \& detracto, c.etâ, vt abà, home, ou homes, abàeta, homes, oca, casa, 1. casas, ócetà, casas (ANCHIETA, 1595: 38).

Às vezes, os equivalentes vão acompanhados de explicações estruturais, traduzidos ao português; veja-se o Infinitivo:

(5) Se os verbos, donde se determinam, são neutros, acrescentam preposição, ${ }^{16}$ como: folgo que vás xe rorýb nde só resé eu folgo com teu ir. E assim dos mais.

Onde a linguagem o permite, também se pode usar da maneira sobredita, como: quero ir $a-i-p o t a a^{\prime} x e$ só que soa: eu quero o meu ir. ${ }^{17}$

A fórmula "que soa" indica a verdadeira estrutura do tupi. Podese verificar que Anchieta, conhecendo, portanto, o tupi profundamente, na gramática, respeita o método canônico tanto para o ensino do latim como para o saber dos alunos.

A gramática de Anchieta está, em forte medida, penhorada ao Humanismo Vulgar, determinante da tradição latina. Mesmo que a projeção sobre o latim deixe pouco espaço à descrição genuína do tupi, é notável o fato de Anchieta tentar descrever, ao lado do espelhamento no latim, as genuínas estruturas do tupi.

Em geral, é preciso distinguir quatro aspectos / etapas bastante diferentes:

1 O domínio do idioma indígena do qual Anchieta pode dizer por si mesmo: "Quanto à língua, eu estou nella tanto adiante, ainda que he muito pouco para que a soubera";

$2^{\circ}$ A descrição metalingüística que, apesar de diferenças consideráveis (incomensuráveis), terá de seguir o modelo clássico; 
3o O procedimento dos missionários que se baseia no: reduzir em gramática, isto é, estabelecer regras que facilitem e permitam ao missionário encontrar equivalentes às categorias gramaticais do latim / ou do vulgar;

4ำ A mudança paradigmática na descrição das línguas ameríndias com a Gramática Mexicana de Wilhelm von Humboldt (ca. 1821-1830), (1866).

\section{A MUDANÇA PARADIGMÁTICA DA GRAMATICOGRAFIA DAS LÍNGUAS AMERINNDIAS}

\subsection{A atividade da missão na Nueva España}

Os missionários (sobretudo os Jesuítas) - tanto no Brasil para os tupinambás, quanto na América espanhola - estavam interessados na catequização dos indígenas nos idiomas da terra. Este fim orientou a gramaticografia ${ }^{18}$ e conduziu à redação de gramáticas, destinadas

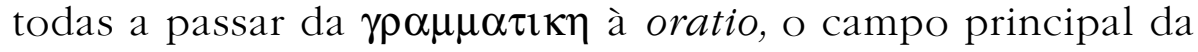
catequese. Para a oração e a catequese, é preciso traduzir, conservando, nas línguas indígenas, a forma e o valor sagrados do texto.

Com isso, os alunos que desconhecem o latim vão traduzindo da língua vulgar para as línguas dos índios, enquanto que o ensino da Gramática se faz seguindo o modelo da Ars Grammaticae, conhecendo os professores do colégio, o latim.

Um outro aspecto é a dignificação da língua descrita. ${ }^{19}$ A dignidade das línguas de catequese constitui um aspecto de maior importância, de modo a rastrear as línguas dos naturais da terra sobre o latim: o nobre alvo consiste em manter a dignidade do texto, isto é, garantir que não possa quedar em falas incontroladas de povo inculto. $\mathrm{O}$ alvo é manifestar a diferença entre Palavra de Deus e discurso vulgar. ${ }^{20}$

\subsection{As primeiras gramáticas dos missionários}

Tal orientação é óbvia na descrição do nabuatl, no México, constituindo prova disso as gramáticas de $\mathrm{Olmos},{ }^{21}$ o vocabulário de 
Molina, ${ }^{22}$ igualmente a Arte Mexicana de Rincón (1595) ${ }^{23}$ contemporanêa à de Anchieta. Não carece referir que tanto Olmos como Rincón já exprimiram dúvidas de que um idioma tão particular como o nahuatl se possa descrever e ensinar com o modelo latino:

No es posible guardarse en todo vn mismo methodo y arte, en enseñar todas las le[n]guas, siendo ellas (como lo son) ta[n] distantes e diferentes entre si, antes la vniformidad en esto seria gran disformidad, y por consiguiente confussion y estouro para quien las deprendiesse. Mas con todo esso no se puede negar que el camino mas llano y breue para aprouechar en qualquiera de las lenguas, es, el que an hallado la latina, y griega, como se vee por el artificio con que se enseñan y aprende[n]: [...] (RINCÓN, 1595, apud SMITH STARK, 2000: 33).

Os missionários, mesmo conscientes do problema das diferenças estruturais, vão, não obstante, aplicar a grelha do latim, de gramática "espelho da língua latina”, experimentada como base didática. As estruturas genuínas dos idiomas ficam sacrificadas ao fim didático. ${ }^{24}$

As particularidades estruturais, às vezes, são integradas - em explicações - no texto descritivo, permanecendo o latim como princípio geral. As gramáticas missionárias nunca têm o empenho de redução a regras conforme o gênio da língua indígena, empenho de estrutura adequada. Assim, não é errado falar de "método de hibridez", óbvio já com Andrés de Olmos (1547):

Y ansi van tambien otras cosas en esta arte, que no se pueden bien sacar de los terminos latinos, y ponerlo en terminos ynteligibles a todos no se puede bien hazer. Y ansi en muchas cosas lleva la traça de la gramatica latina assi porque se vea el artificio de la lengua no ser tan barbara como algunos dizen, como porque con gran dificultad y prolixidad, no se pudiera dar todo a entender por solo nostro romance, sin mezclar algo del latin. (OLMOS, 1875: 137-138, apud HERNÁNDEZ SACRISTÁN, 1997: 48).

\subsection{A dignificação da língua exótica}

Com Olmos, outro aspecto já fica saliente: "la dignificación de la lengua descrita", ${ }^{25}$ o que significa que a estrutura dos idiomas 
ameríndios não é tão bárbara como alguns pretendem. A dignidade é um aspeto importante que, entre outros, abrange o seguinte: sendo feitos para evangelização e catequese, os textos missionários em língua ameríndia têm que sumamente respeitar o original latino: "Até à ordem das letras" (como diz São Jerônimo). ${ }^{26}$ A versão latina da Bíblia ou de outros textos eclesiásticos tem sido considerada sagrada "Até à ordem das letras." Hernández Sacristán comenta:

Aunque estas [...] funciones puedan considerarse marginales desde el punto de vista científico moderno, constituyen perpectivas que explican y justifican el producto histórico que son las gramáticas misioneras. ${ }^{27}$ (1997: 48-49).

É óbvio o fato de, justamente nessa época, não ser possível contar com descrições objetivas ou neutras das línguas ameríndias, sendo as Artes de Gramática dominadas pela finalidade. Dentro da tríade: assunto-descrição-finalidade, as gramáticas missionárias têm a finalidade como dominante.

Em outros casos, o interesse se volta mais para o funcionamento da língua do que para o emprego da Arte (catequese). Aqui se distinguem dois homens: Horácio Carochi, padre italiano e Wilhelm von Humboldt. Ambos encontraram princípios adequados para descrever o nabuatl, Carochi em 1649 e Humboldt por volta de 1810, cabendo a Humboldt o mérito de descrever o nabuatl como lingua incorporante. É uma classificação exata que Humboldt descobre com base nos estudos da língua basca (em 1799-1801).

\section{FORMA INTERNA E INCORPORAÇÃO COM VON HUMBOLDT}

\subsection{Humboldt e a alteridade das línguas exóticas}

Ao longo de anos de estudo das línguas não-européias, Humboldt chegou a algumas idéias sobre a sua alteridade e o seu caráter dissemelhante. Ele se debruçou sobre várias dessas línguas, cujas estruturas lhe pareciam fundamentalmente diferentes daquelas línguas européias. Escreve ele que 
A estrutura curiosa de várias dessas línguas deveria ter despertado muito mais cedo e continuadamente a atenção dos lingüistas, se o seu tratamento não tivesse feito tudo para tornar irreconhecíveis as salientes particularidades estruturais. ${ }^{28}$

A tese de Humboldt consiste em afirmar que as línguas constituem organismos vivos, de que resulta terem de ser descritas tanto nos seus constituintes como no seu funcionamento. Ele está profundamente convencido de que a adaptação a modelos descritivos da tradição greco-latina desvia o olhar das verdadeiras estruturas das línguas e, desse modo, a descrição adequada se torna impossível. As línguas, tal é o ponto de vista de Humboldt, necessitam de uma descrição que respeite a sua natureza de forma a abranger a sua alteridade e que não se contente em espelhar meramente o latim.

Um tal tratamento que lhes atribui sistemas aparentemente comparáveis às nossas línguas não forneceu um sistema de regras capaz de dar conta da alteridade dessas línguas ou um sistema de regras que permita alinhá-las, e quando essas particularidades foram mencionadas, então só o foram a título de exceções, locuções e solecismos.

Os esforços de Humboldt orientavam-se, todavia, no sentido de descobrir o organismo - na verdade, muito diverso - inerente a essas línguas. Estava bem consciente de que a descrição gramatical dessas línguas teria então de ser refeita completamente: "De cada uma dessas gramáticas deve surgir uma nova que seja mais consentânea com a natureza da língua." ${ }^{29}$ Esta mudança de paradigma relativa ao modo de ver, de pensar e de descrever, postulada por Humboldt, contém, pelo menos, três etapas aptas para revolucionar a descrição das línguas exóticas:

1. a consciência da disparidade e da estranha alteridade da estrutura;

2. a observação minuciosa do material lingüístico para descobrir as diretrizes da estrutura insólita;

3. a tentativa de uma descrição coerente e adequada da língua exótica.

Partindo da forte convicção de que a matéria lingüística, que se lhe apresentava, deveria ser organizada, Humboldt conseguiu 
derivar um sistema de regras a partir dos fragmentos a que tinha acesso nas gramáticas dos missionários e assim reconhecer as estruturas gramaticais autóctones. Neste contexto, a idéia que Humboldt teve do princípio gramatical da incorporação representa um marco da maior importância para a descrição da língua mexicana, assim como para a descrição lingüística em geral. Humboldt descobre um dos princípios nucleares da organização gramatical do Nabuatl. Tão central que, a partir dessa linha diretriz, compreende-se a estrutura organizativa das partes importantes da sintaxe e da formação de palavras! Essa descoberta parece genial, porque, na História da Lingüística, à epoca, ela constitui um achado único. Só parece possível no quadro de uma pesquisa incansável que investigue os ínfimos pormenores e pressupõe um olhar ousado e genial perante os relacionamentos das partes com o todo.

Esta foi a base para conferir à descrição do Nabuatl uma forma concludente e de coerência interna, pois correspondia pela primeira vez ao caráter singular dessa língua exótica.

\subsection{A forma interna da língua}

Humboldt estabelece o princípio de incorporação como princípio da interiorização lingüística do mundo real, avaliado, às vezes, como cosmovisão lingüístico-cultural diferente. As gramáticas missionárias, por seu lado, não lograram captar o verdadeiro princípio estrutural das línguas ameríndias, princípio estrutural que, segundo Humboldt, transparece na língua, constituindo a forma interna (Innere Sprachform). Ela é a base da interiorização do mundo exterior e da reflexão dos fatos exteriores, as duas, bem entendido, organizadas de modo sensivelmente diferente nas línguas ameríndias e nas línguas indo-européias. No entanto, o princípio estrutural, para Humboldt, tem um sentido muito mais largo do que com Ferdinand de Saussure. Abrange o mérito da língua como portadora de espírito, cultura e civilização de povos e nações, considerada como "a emanação do espírito dos povos”. (HUMBOLDT, 1963: 414) 
Estão aí os fundamentos daquele princípio da Innere Sprachform, quase mitológica, e base de maiores confusões e disputas entre lingüistas e filósofos, que continuam desde a publicação da Obra do Kaui em 1836, de cujas idéias tantos queriam se "apropriar". Humboldt, no capítulo sobre a forma interna da lingua, escreve:

[...] todas as pré-excelências das formas fônicas, realizadas com arte e ricas de sonoridade, também ligadas ao mais vivo sentido articulatório, não seriam, todavia, capazes de produzir línguas convenientes ao espírito, se a radiante clareza das idéias relativas à língua não as penetrasse com a sua luz e o seu calor. Essa parte, totalmente interna e inteiramente inteletual, é, em verdade, a parte constitutiva da língua; ela é o uso para o qual a produção linguageira se serve do elemento fônico, e nela se baseia esta faculdade da linguagem que consiste em saber exprimir tudo aquilo que, com o progresso da atividade inteletual, as maiores cabeças das gerações ulteriores desejariam the confiar. Esta sua natureza depende da concordância e do concurso em que finalmente estão sendo encontradas as leis manifestas nela, seja em relação recíproca, seja em relação com as leis do intuir, do pensar e do sentir.(HUMBOLDT, 1963: 463-464 - tradução nossa).

Levou bastante tempo até tal visão ter amadurecido no ideário de Humboldt, e poderia parecer especulação teórica sobre a filosofia da língua, mesmo na Obra do Kaui "Sobre a diversidade das estruturas lingüísticas da humanidade”. Mas não o é! É palpável na Gramática Mexicana como resultado das investigações de Humboldt sobre as línguas exóticas, sobre línguas que - comparadas ao tronco indoeuropeu - apresentam estruturas tão diferentes. Está claro que tais inteligências deviam amadurecer no pensamento de Humboldt, o que pressupõe, além disso, certas condições felizes no processo cognitivo.

\subsection{O princípio da incorporação com von Humboldt}

Tal como Champollion decifrou os hieróglifos dos egípcios na base da língua copta, Humboldt descobriu a incorporação na base do conhecimento do basco. Reencontra a incorporação depois no 
nabuatl. É, no fundo, um princípio estrutural possível de encontrar em línguas ergativas, empenhadas, às vezes, (línguas indiciantes) na indicação da forma verbal do caso objeto - em prefixo ou infixo o que é condição para se falar de línguas oni-predicacionais, termo recente, forjado por Launay: Humboldt, neste caso, usa o termo de incorporação ("Einverleibung”). Já em 1811, escreve:

Il y a deux pronoms suffixes d'une signification indéterminée; l'un exprimant une personne, l'autre une chose quelconque. On pourroit cependant aussi regarder ces deux soi disants pronoms comme deux particules servant à indiquer à quoi se réfère un verbe, ou un nom verbal, comme à son régime. (HUMBOLDT, 1994: 204)..$^{30}$

e continua:

Le Verbe ne se trouve jamais, ou au moins très rarement ác'est à dire uniquement dans la 3. pers. du singulier du présent des verbes simples intransitifsñ seul, mais toujours accompagné de différents pronoms, (1) áetñ terminaisons. (HUMBOLDT, 1994: 204). ${ }^{31}$

para realçar, não sem surpresa, as características tipológicas da incorporação:

(6) [...] le régime du verbe lui est incorporé comme pronom accusatif, et suit alors immédiatement le pronom nominatif. Ce cas a lieu non seulement quand le régime est vraiment un pronom, mais aussi quand c'est un substantif séparé du verbe, comme cela se pratique dans nos langues. Ti-nech-mictia "tu me tues"; ni-c-tlaça in tlaxalli "je le jette, le pain". (HUMBOLDT, 1994: 205). ${ }^{32}$

e resumir mais tarde:

La langue Basque est la seule, autant que je sache, qui partage cette dernière particularité d'ajouter au verbe un pronom accusatif de 3 e. personne lors même que le régime du verbe est exprimé par un substantif séparé. (HUMBOLDT, 1994: 205). ${ }^{33}$

A comparação com o basco, onipresente em 1811, já vem mais tarde reduzida em importância na Gramática Mexicana. Por enquanto, é óbvio que a percepção das particularidades do nabuatl resulta da comparação com aquela língua. 
É preciso insistir em dois pontos: por um lado, as construções, ou melhor, composições ou derivações e, por outro lado, o ideário metalíngüístico que favorece o termo incorporado. A particularidade do nabuatl já foi descrita, e até minuciosamente, na Gramática de Carochi (1645) e pelos seus discípulos. Von Humboldt foi o primeiro a descobrir o princípio diretor da gramática do nabuatle criou o termo incorporado, adequado ao fenômeno. Assim, a descrição metalingüística passa a dispor de uma linha diretora, adequada ao idioma.

(7) Qui-cua in pilontli in nacatl. ("A criança come a carne"). a/c.-comer-DEF-criança-DEF- DEF carne-DEF.

Launay nota neste contexto:

Le préfixe qui- (/ki-/, qui a une variante $/ \mathrm{k}-/$, écrite qu- ou c-, le /i/ de / ki- / étant une voyelle d'appui évitant les groupes de consonnes internes à la syllabe) est ici une marque d'objet $3 \mathrm{e}$ personne du singulier. (LAUNAY, 1994: 37) ${ }^{34}$

Não é possível omitir o pronome: (7.1) *Cua in pilōntli in nacatl. Comentário de Humboldt:

(8) Les verbes applicatifs se forment de la même manière que les transitifs dont le régime est un simple pronom [...] avec la seule différence qu'on leur ajoute à la fin pour la plupart, mais pas toujours, la terminaison lia. Ni-c-chihui-lia in no-piltzin in calli, je bâtis une maison pour lui pour le mon fils. La langue Basque insère dans ces deux pronoms, un accusatif et un datif dans le verbe." (HUMBOLDT, 1994: 205).35

No ideário de von Humboldt, o esquema categorial da língua não pode ser alcançado por projeção interlingual, projeção do latim, idioma de prestígio, sobre o idioma ameríndio. Ele não se satisfaz com a grelha funcional, resultado de equivalências entre língua-fonte e língua-alvo. O seu empenho consiste em descobrir o funcionamento intrínseco da língua, perceber a sua forma interna (Innere Sprachform), base e finalidade das regras da Arte. 


\subsection{O tratamento dos possessivos}

Um paradigma gramatical no qual o nabuatl difere do espanhol é o dos possessivos. O seu tratamento é mais uma prova da inconseqüência ou falta de decisão na gramaticografia. Tal tendência continua até Humboldt. É evidente, nesta ordem de fatos, que o princípio de incorporação vale mesmo para os possessivos. No entanto, o tratamento anda tão ligado à tradição que não se consegue renunciar à denominação Pronome.

As descrições modernas conhecem a distinção estrita entre "forma absoluta" e "forma possuída", caminho para distinguir as formas com artigo definido e as restantes (LAUNAY, 1992: 89). A gramaticografia orientada pelo latim tem escrúpulos em deixar de categorizar em pronomes os indicadores possessivos incorporados. A única exceção é a gramática de Carochi, adaptada em 1759 pelo Pe. Ignácio de Paredes. Aqui, os possessivos se tornam semipronomes. A gramática, usada para o ensino dos índios, explica, de maneira exemplar e contrastiva, as diferenças de possessivos em espanhol e nahuatl.

(9) Como todas las lenguas tienen algunos modos de hablar que son en ellas elegancias y fueran en otras barbarismos, así también la Lengua Mexicana tiene algunos mexicanismos ó modos propios de hablar, [...]

Primeramente carece esta lengua de los pronombres posesivos y absolutos que puedan por sí solos estar en la oración y significar, y son: mio, tuyo, suyo, nuestro, vuestro. suyo ó de aquellos. Quiero decir: En esta lengua no se puede formalmente decir, este sombrero es mío, esa capa es tuya ó nuestra. [...]

Sino que para este se vale del nombre axcaitl, ó tlatquitl, ó yocauh, que significan cosa alhaja ó hacienda, y a uno de estos se junta uno de los semipronombres que le corresponde y que son no, mi, $i$, etc., mío, tuyo, etc. Y así para decir, esta casa es mía, se dice, inin calli, ca naxca ó notlatqui ó noyocauh, como si dijera, esta casa es mi cosa propia, mi alhaja, mi hacienda ó cosa que me toca. (CAROCHI / PAREDES, 1910: 75). ${ }^{36}$

Parece uma descrição equilibrada e, sobretudo, marcada pela ausência de preconceitos para com as línguas ameríndias. A 
atribuição do rótulo de elegância/barbarismo revela a visão tolerante e imparcial dos autores da gramática do nabuatl.

\subsection{As diáteses verbais da língua mexicana}

Sendo as diáteses um pivot estrutural do nabuatl, elas ocupam em Humboldt um lugar de destaque. É uma área do maior interesse para o nabuat, o qual manifesta grande mobilidade de estruturas argumentais. Aqui empregamos o termo de "diátese", ausente na obra de Humboldt. Ele, neste contexto, costuma falar (sem termo propriamente gramatical) de "verbos derivados de verbos"(HUMBOLDT, 1994: 137), explicando em pormenor:

Existem categorias que indicam as relações com o verbo e que lhe são essenciais, mesmo que não presentes em todas as línguas com formas próprias. Desta espécie são Ativa, Passiva, Deponentia, Impersonalia, etc. No entanto, há outras categorias que, sem marcarem tais relações, só aparecem graças a certas modificações do significado dos verbos, praticáveis com todos (os verbos) ou pelo menos com alguns, e às quais a língua atribuiu uma categoria gramatical própria.' (HUMBOLDT, 1994: 137 - tradução nossa).

Esta passagem contém várias das idéias de Humboldt sobre princípios estruturais das línguas. Visto as estruturas serem sensivelmente divergentes, só com extrema cautela se poderia pensar em orientar a gramática descritiva pelo latim ou pelo grego. O que é tratado em Humboldt é: Actiua, Passiua, Deponentia e Impersonalia, tal como se encontram em latim, admitindo-se, além disso, outras categorias (Gattungen) que:

[...] devem a sua existência só ao fato de a língua reservar uma forma própria gramatical, para certas modificações do significado verbal que é possível atribuir a todos ou pelo menos a vários. ${ }^{37}$

Os termos da categoria das diáteses são de "particularidade nacional" e pertencem ao sistema categorial da língua.

A língua mexicana conhece uma perfeição rara na expressão das várias relações do verbo, no entanto não é rica em outras formas 
acidentais e o que lhe é completamente estranho é o tratamento regular dos sons das raízes. (HUMBOLDT, 1994: 138 - tradução nossa).

O que interessa é "a perfeição rara na expressão das várias relações do verbo”, isto é, o sistema cunhado por diáteses. Vejamos alguns dos membros da categoria.

Os compulsiva e applicativa se formam com terminações que são indiciadas. É sensível o empenho do autor em criar terminologia. Os morfemas ${ }^{38}$ são anexados (angehängt). Humboldt explica de que modo e por que meios articulatórios isso ocorre. O que aqui é importante é a incerteza entre Anheftung, Anbängung e Anbindung (ligação/laço) que, de fato, se usam de modo mesclado, mas que, finalmente, não têm significado idêntico. Anbindung é o mesmo que um afixo derivado, prefixo ou sufixo; Humboldt sabe que, num sistema incorporante, terá que contar com ambas as soluções.

Ele também emprega o termo de "primitiuum", termo que na sua obra equivale a base derivativa e serve para visualizar várias operações derivativas, o que Humboldt chama de modificações. Explica depois as marcas dos compulsiua: tia, ctia, ltia e buia, sendo $\mathrm{o} / \mathrm{c} /$ uma variante morfológica de tia, visto que /c/ vem de ca, qui (como marcas da $3^{\text {a }}$ ps. acusativo). É característico o fato de Humboldt empregar o termo de casos como nominatiuus ou accusatiuus, em vez de termos funcionais como sujeito ou objeto. Talvez seja cautela, dado que ele está consciente, pelos estudos do basco, do problema das línguas ergativas. No entanto, a Gramática Mexicana não contém o cunho de línguas ergativas.

\subsection{Comparação com Carochi (1645): Compulsiua}

O termo de Compulsiua se aplica com Carochi a causativos do nahuatl. Eles têm, como já se disse, as marcas / ou sílabas -tia / -ltia.

(10) [...] niyōli (viver) nicyolītia, le hago viuir; le doy vida, [...] ninemèni, yo ando; nicnèmītia, vel nicnèmiltia, le hago andar. (CAROCHI, 1910[1759]: 464). 
(11) [...] nicholoa, yo huygo: nicchololtia, hagole, o persuadole a que se huiga [...] (CAROCHI, 1910[1759]: 464).

Carochi está empenhado em formular regras compreensíveis. Todavia, mesmo que não chegue a descrever a estrutura interna da língua, fixando em regras as suas particularidades, é evidente que se trata de uma gramática bem organizada, obedecendo já a outros princípios estruturais, diversos dos das artes vulgares européias. Carochi descreve vários grupos ramificados de causativos. O grupo que se segue são os aplicatiua. ${ }^{39}$

\subsubsection{Verbos aplicativos}

A distinção entre aplicativos, outro grupo de causativos, e compulsiva é bastante sutil. Diz Carochi:

(12) VERBO aplicatiuo es el que ordena la accion del verbo a otra persona, o cosa, atribuyendosela por via de daño, o prouecho, quitandosela, o poniendosela, o refiriendosela de qualquer manera que sea, como se entenderá por los exemplos; verbi gracia: nitlaqua, como algo, nictnaquālia in notàtzin, como algo a mi Padre, como si tenia fruta o otra cosa, y se la como. (Carochi 1910 [1759]: 466). ${ }^{40}$ (12.1) ni-tla-qua (eu-COMER-a/c.) => ni-c-tna-qua $\bar{a}$-lia in no-tà-tzin [eu-isso-COMER-a/c.-a alg.] DEF-eu-pai-REV).

(12.2) ta-tli - pai-DEF. $=>$ no-ta-tzin (eu-pai-REV.)

(13) Onēehtlaquāliquè in moquāquabuècāhūān, tus bueyes me han comido algo, que es la sementera, me han hecho daño, onēchtlaquāliquè in nomīl, onēchtlaquāliquè, me han comido mi sementera, me han hecho daño." (CAROCHI, 1910 [1759]: 466).

Tal tipo de causativo é uma conceitualização inusitada nas línguas indo-européias, isto é, pertence à "forma interna da língua" diferente. Carochi, originário de Veneza, sabia hebraico ${ }^{41}$ e estava empenhado em dotar o nabuatl de uma descrição que correspondesse à sua estrutura intrínseca. É provável que o conhecimento do hebraico o ajudasse nisto. Sai da grelha do latim, mesmo dos idiomas indoeuropeus, talvez sem ter consciência completa do alcance teórico disso. Faz, todavia, comparações com outra Língua Sagrada - o 
hebraico (tronco do caldeu) chegando a soluções viáveis e adequadas à estrutura do nahuatl.

\subsubsection{O princípio incorporante com Carochi}

Tudo o que com Humboldt se chama incorporé ou Einverleibung (incorporação), encontra-se, como estado de fatos, já em Carochi/ Paredes (1759), ${ }^{42}$ só que aqui se trata apenas do título de Composición: Composición de nombres, y verbos, y otras cosas. ${ }^{43}$

Enquanto se trata de Composición de substantivos, o princípio estrutural não se torna tão evidente. Acontecem mesmo certas modificações das estruturas gramaticais. Parece seguir, de fato, mais ou menos, um princípio de alinhamento (Anreibung).

Isto acontece de modo diferente do qual Carochi trata da composição de substantivos. Neste caso, começa por distinguir entre Actiua, Neutra e Passiua. Não só se descrevem princípios estruturais, comparáveis aos do basco, mas também é visível o valor proposicional da estrutura verbal que indicia o/os objeto(s), quer se trate de patiente, instrumento ou sintagma comparativo.

(14) Los nombres se componen tambien con verbos, y quando el nombre se compone con verbo actiuo, y éste no tuuiere otro nombre paciente (que se conocerá en que no tiene nota de transicion) entonces será paciente el compuesto; verbi gracia: nixōchitemoa, busco flores, [...] (CAROCHI, 1910 [1759]: 475). ${ }^{44}$

(14.1) ni- xōchi- temoa

yo- flores- buscar

De outro modo, quando o paciente fica expresso por nome, então o composto interior tem a função de instrumento, o semejança»: nicxōchitemoa cuīcatl

$$
\begin{array}{rl}
\text { (14.2) ni }-\mathrm{c}-\mathrm{x} \overline{\mathrm{c}} \mathrm{ch}-\mathrm{temoa} & \mathrm{cu} \bar{\imath} \mathrm{ca}-\mathrm{tl} \\
\mathrm{eu}-\mathrm{a} / \mathrm{c} .- \text { flores - buscar (como) } & \text { rosa -DEF }
\end{array}
$$

ainda mais óbvio em: "nictlehuatza in nacatl, asso la carne, in verbum, seco la carne al fuego" (CAROCHI, 1910 [1759]: 475): 


$$
\begin{aligned}
& \text { (15) ni - c - tle - huatza in } \\
& \text { eu-a/c. - fogo }- \text { secar (como) carne -DEF }
\end{aligned}
$$

No passivo, as funções se alteram. Então, o elemento composto se torna "semejança. instrumento o paciente", veja-se: (16) "ōtléhuātzaloc in nacatl, se assó la carne con fuego” (CAROCHI, 1910 [1759]: 475):

$$
\begin{array}{rlll}
(16.1) \bar{O}-\text { tlé }- \text { huatza }- \text { loc } & \text { in } & \text { naca - } \mathrm{tl}^{45} \\
\text { PASS - fogo - secar - tornar-se } & \text { (como) } & \text { carne -DEF }
\end{array}
$$

Assim, o princípio incorporante da forma verbal fica claramente marcado. A forma verbal integra todas as partes constituintes da proposição. Todavia, enquanto Humboldt declara isso um princípio que não conhece exceções, é possível entrever com Carochi que, ao marcar os agentes da frase (a forma interna do nabuatl), disponha, também, de margens de mobilidade.

\section{CONCLUSÕES E PERSPECTIVAS}

Wilhelm von Humboldt que, por interesse antropológico, estudou o basco, apercebeu-se, muito cedo, de que o saber sobre o gênero humano, a existência social, a cultura e os costumes não anda separado de língua e de linguagem. Assim, ele já cedo se interessa pela variedade das línguas humanas. Durante trinta e cinco anos, dedicou-se a estudos lingüísticos, ao estudo e à descrição de "línguas exóticas".

Às vezes, foi uma busca desesperada, trabalhando com penúria de materiais: de gramáticas e textos insuficientes onde se detectavam as estruturas língüísticas. No entanto, nos estudos lingüísticos e linguo-filosóficos permanece o fio condutor de sua vocação científica, de sua vida. É conforme ao interesse científico que Humboldt escolhe os lugares da função diplomática fora da Prússia; e quando eliminado do governo, refugia-se no estudo da diversidade das línguas do gênero humano.

Tudo isso terá que se considerar quando for rendida homenagem à obra de Humboldt, lingüista e filósofo. Uma característica de Wilhelm von Humboldt durante a vida toda é a constante 
inclinação ao ceticismo: pôr em dúvida as próprias idéias, escritos e resultados, expressão de modéstia por parte de um espírito ilustre, aliás bem visível numa missiva endereçada a Goethe, em 2 de novembro de 1831:

Passei os meses de julho e agosto no extremo do litoral norte da Alemanha e as caldas marítimas (Norderney - Autor) restabeleceram as minhas forças mais do que eu podia esperar. Agora continuo me ocupando de estudos de língua. Não oculto a mim mesmo que eles, às vezes, são muito minuciosos; no entanto, não consigo me separar deles. Tem-se a impressão de que o fio, uma vez ligado, devia ser tecido até ao fim, e isto, no fundo, é também o conteúdo da vida. Pois, aquilo que alguém consegue criar, mesmo aos próprios olhos, nunca tem o valor do progresso contínuo. (HUMBOLDT, 1953: 939 tradução e grifo nossos)

O significado é múltiplo. Tal como Hegel disse que um adágio em boca de idoso tem significado muito mais profundo do que em boca de adolescente, a passagem epistolar está carregada de sentido profundamente filosófico.

Dois meses depois, no dia 6 de janeiro de 1832, Humboldt escreve a Goethe (será a última carta): ${ }^{46}$

Eu também me sinto mais do que nunca com gosto de trabalhar. No entanto, muito do que consegui escrever, foi no Mar do Norte (...). No entanto, tenho a impressão de que eu talvez tenha atingido mais do que nunca até hoje o ponto para o qual convergem todos os meus trabalhos e estudos anteriores. Vejo nisso a admoestação para não confiar muito no tempo que me resta, mas para aproveitar o presente deixando atrás de mim aquilo que posso sentir, mas que está dentro de mim, sempre não desenvolvido e em parte não provado, ao mesmo tempo chegar a apresentá-lo e levar comigo e deixar atrás de mim. Pois, ambos se ligam na minha imaginação. Possui-se nas idéias por completo só aquilo que foi possível apresentar fora de si e transmitir aos outros, e por mais obscuro que seja tudo aquilo que exista para além da vida, eu não posso considerar de maneira indiferente, se - antes de falecer - uma pessoa conseguir chegar ou não à verdadeira clareza do que queria atingir nas idéias ao longo da vida. Assim como a individualidade não se pode perder e assim como no mundo há dois rumos que formam 
o tecido histórico como ascensão e queda, a existência descontínua do indivíduo e a evolução contínua da vida, são, deste modo, como que a cadeia que o destino criou com a sua ajuda; e eu, simplesmente, não posso deixar de ver a parte principal no indivíduo, que, por assim dizer, leva à evolução do Mundo, como conseqüência necessária. Por isso, a clareza perante si mesmo permanece - mesmo que não possa perder muito - o motivo mais urgente de um trabalho incessante, e sinto-me feliz por este ter agora um rumo mais sólido. (HUMBOLDT, 1953: 943/944 - tradução nossa).

Tal transição para a clareza coincidiu com o último período criativo de Humboldt, pois logo em seguida, por volta de 1833, as suas forças começaram a diminuir, iniciando-se o período de enfermidade, ficando o grande pensador ao cuidado da filha Caroline. Neste resumo de existência não será sem interesse ouvir a voz de Goethe que, conhecendo a luta do jovem Humboldt para exceler em poesia e lembrando-se do seu naufrágio nesta arte, escreve a Humboldt, cinco dias antes da sua morte e com respeito a si mesmo:

Aqui mesmo, é verdade, se estava apresentando a grande dificuldade para conseguir por via de propósito e perseverança aquilo que, no fundo, seria obra da natureza espontânea. No entanto, não era bom, se isso, depois de vida intelectual tão longa não houvesse sido realizado, e estou sem receio: será possível distinguir o mais antigo do mais novo, e o ulterior do anterior; o qual depois gostaríamos de entregar ao benevolente conhecimento de futuros leitores. ${ }^{47}$

Wilhelm von Humboldt alcançou tudo por perseverança. Não tendo encontrado no berço este gênio, às vezes, brincalhão de Goethe, nem a ligeireza do irmão Alexandre, foi com desassossego cético e meticulosidade inteletual, com caráter e perseverança, que ele findou as obras que hoje estamos admirando com espanto por parecerem sem igual na história da filosofia da linguagem. Para descrever a forma interna das linguas ameríndias, a contribuição de Humboldt tornou-se um marco decisivo. 


\section{NOTAS}

${ }^{1}$ Gândavo (1995: 98; 100).

${ }^{2}$ Gândavo (1995: 100).

${ }^{3}$ No México, só a partir de 1572.

${ }^{4}$ Manuel de Nóbrega (1517-1570).

${ }^{5}$ José de Anchieta (1533-1597).

${ }^{6}$ Cf. Autor (2001).

${ }^{7}$ No Brasil, a política portuguesa de mestiçagem (as mães foram mulheres tupi) levou à divulgação duma variação do tupinambá, duma espécie de lingua franca.

${ }^{8} \mathrm{Cf}$. planos para o estabelecimento de províncias absolutamente eclesiásticas no Paraguai e no Maranhão.

${ }^{9}$ Karl Wilhelm von Humboldt (1767-1835).

${ }^{10}$ Humboldt (1994: 4).

${ }^{11}$ Cf. Ringmacher (1994: 76).

${ }^{12}$ Humboldt (1994: 222).

${ }^{13} \mathrm{Na}$ tipografia de Antônio Mariz.

${ }^{14}$ Nebrija, Arte de grammatica, A. Quilis (ed.)1989: 105.

${ }^{15} \mathrm{O}$ que as gramáticas ulteriores (cf. Luís Figueira, S.J., ca 1574-1643) só fazem em medida reduzida.

${ }^{16}$ Trata-se, no fundo, de pós-posições.

${ }^{17}$ Anchieta (1595: 27r.)

${ }^{18}$ Tratado in extenso por Hernández Sacristán (1997), como funcionalização da gramaticografia.

${ }^{19}$ Cf. Hernández Sacristán (1997: 48).

${ }^{20}$ Nesta perspetiva, tratando-se da Palavra de Deus, seria preferível empregar uma expressão incomum empregar a dos camponeses.

${ }^{21}$ Fim do séc. XV - 1571.

${ }^{22} 1514-1585$.

${ }^{23} 1556-1601$.

${ }^{24}$ Hernández Sacristán: instrumentalização da gramaticografia. 
${ }^{25}$ Aspecto destacado por Hernández Sacristán (1997: 48).

${ }^{26}$ S. Jerônimo, carta a Pamacchio.

${ }^{27}$ Mesmo que estas funções possam se considerar marginais do ponto de vista científico moderno, constituem perspectivas que explicam e justificam o produto histórico que são as gramáticas missioneiras. (1977: 48-49. Tradução nossa)

${ }^{28}$ Humboldt (1903 - 36; VI: 135).

${ }^{29}$ Humboldt (1903 - 36; VI: 135).

${ }^{30}$ Existem dois pronomes sufixos de significado indeterminado: um que exprime uma pessoa, o outro que exprime uma coisa qualquer. Seria possível, portanto, ver esses dois pretensos pronomes como duas partículas que servem para indicar a que se refere um verbo, ou um nome verbal, em função do seu regime respectivo. (Humboldt, 1994: 204. Tradução nossa).

${ }^{31} \mathrm{O}$ verbo não se encontra nunca, ou pelo menos raramente (na $3^{\mathrm{a}}$ pessoa do singular do presente dos verbos simples intransitivos), sozinho, mas sempre acompanhado de vários pronomes e terminações. (Humboldt, 1994: 204. Tradução nossa).

32 [...] o regime do verbo é nele incorporado como pronome acusativo, seguindo assim imediatamente o pronome nominativo. Este caso dá-se não só quando o regime é verdadeiramente pronome, mas também quando se trata de um substantivo separado do verbo, tal como acontece nas nossas línguas Ti-nech-mictia "tu me matas"; ni-c-tlaça in tlaxalli "eu o jogo fora, o pão". (Humboldt, 1994: 205. Tradução nossa)

${ }^{3}$ A língua vasca é a única, tanto que eu saiba, a partilhar esta última particularidade de juntar ao verbo um pronome acusativo da $3^{a}$ pessoa, mesmo quando o regime do verbo é expresso por um substantivo separado. (Humboldt, 1994: 205. Tradução nossa).

${ }^{34} \mathrm{O}$ prefixo qui (/ki/ que tem uma variante /k-/ escrita qu- ou c-, o /i/ de /ki-/ sendo uma vogal de suporte para evitar grupos consonânticos internos à sílaba) é aqui uma marca de objeto da $3^{a}$ pessoa do singular. (Launay, 1994: 37 . Tradução nossa)

${ }^{35}$ Os verbos aplicativos formam-se da mesma maneira que os transitivos, nos quais o regime é um simples pronome [...] com a única diferença que se tem de juntar no fim, na maioria dos casos, mas não sempre, a terminação -lia. Ni-c-chibui-lia in no-piltzin in calli, construí uma casa para ele, para o meu filho. A língua vasca insere estes dois pronomes, um acusativo e um dativo dentro da forma verbal. (Humboldt, 1994: 205. Tradução nossa). 
${ }^{36}$ Todas as línguas têm alguns modos de falar característicos que são considerados formas elegantes e que, para outras, são barbarismos; assim também a língua Mexicana tem alguns "mexicanismos" ou modos próprios de falar [...]

Primeiramente esta língua carece dos pronomes possessivos e absolutos que por si sós possam ter significado na oração, como: mio, tuyo, suyo, nuestro, vuestro, suyo ou de aquellos. Quero dizer, nesta língua não se pode formalmente dizer: este sombrero es mío, esa capa es tuya ó nuestra. [...]

Com este objetivo aplicam-se os nomes axcaitl, ou tlatquitl, ou yocauh, que significam preciosidade ou fazenda, e a um destes junta-se um dos semipronomes que lhe corresponde e que são: no, mi, $i$, etc., mío, tuyo, etc. E assim para dizer esta casa es mía, diz-se, inin calli, ca naxca ou notlatqui ou noyocauh, como se dissesse esta casa é minha coisa própria, minha preciosidade, minha fazenda ou coisa que me toca. (Carochi /Paredes, 1910: 75. Tradução nossa).

${ }^{37}$ Humboldt (1994: 137/138 - tradução nossa).

${ }^{38}$ Este não é o termo de Humboldt.

${ }^{39}$ Fenômeno interessante é a ordem de tratamento que se dá com as diáteses: começa pelos compulsiua seguidos dos verbos neutros, dos activa e dos passiva).

${ }^{40}$ O VERBO aplicativo é aquele que ordena a ação do verbo a outra pessoa, ou coisa, atribuindo-la por via de dano, de proveito, quitando-la, pondo-la ou referindola de qualquer maneira que seja, como se compreenderá pelos exemplos nitlaqua, como a/c., nictnaqu?lia in notàtzin, como a/c. do meu pai, como se tinha fruta ou outra coisa, e como-a para mim. (Carochi, 1910 [1759]: 466. Tradução nossa).

${ }^{41}$ Da família hamito-semítica.

${ }^{4}$ Pe. Ignácio de Paredes (1703 - ?).

43 Carochi (1910[1759]: 475).

${ }^{44}$ Os nomes se compõem também com verbos, e quando o nome se compõe com um verbo ativo, e este não tivesse outro nome paciente (que se conhecerá pela sua marca de transição) então o composto será paciente, verbi gracia: nix?chitemoa, busco flores, [...] (Carochi, 1910 [1759]: 475. Tradução nossa).

${ }^{45}$ Die Funktion des Morphems tle - von tletl das Feuer - eher als INSTR zu bestimmen, denn als LOC, für LOC wäre tle-co - im Feuer zu erwarten; vgl. Humboldt (1994: 127).

A função do morfema tle - de tletlo fogo - antes deve ser classificado como INSTR do que LOC, contando-se em caso de LOC com tle-co- no fogo, cf. Humboldt (1994: 127).

${ }^{46}$ Goethe vem a morrer no dia 22 de março de 1832.

${ }^{47}$ Wilhelm von Humboldt (1953: 950/ 951- tradução nossa). 


\section{REFERÊNCIAS BIBLIOGRÁFICAS}

ÁlVARES, Manuel. Arte de grammatica. Coimbra: [s.n.], 1572.

ANCHIETA, Pe. Joseph de. Arte de Grammatica da Lingua mais usada na Costa do Brasil - feita pelo P. Ioseph de Anchieta Theologo \& Prouincial que foy da Comonbia de IESU nas partes do Brasil. Coimbra: António de Mariz, 1595. São Paulo: Edições Loyola, 1990.

BARROS, João de. Diálogo em louvor da nossa linguagem. In: BUESCU, Maria Leonor Carvalhão (Ed.). Gramática da lingua portuguesa. Cartinha, Gramática, Diálogo em louvor da nossa linguagem e Diálogo da Viciosa Vergonha, 1540. Reprodução facsimilada, leitura, introdução e anotações. Lisboa: Publicações da Faculdade de Letras da Universidade de Lisboa, 1971. p. 390-410.

CANGER, Una. El Arte de Horacio Carochi. In: ZIMMERMANN, Klaus (Ed.). La descripción de las lenguas amerindias en la época colonial. Frankfurt/M.: Vervuert, 1997. p. 59-74. (Biblioteca Ibero-Americana, 63)

CAROCHI, Horacio. Arte de la Lengua Mexicana: con la declaracion de los adverbios della, 1645. Edição facsimilada (por RUYZ, Juan. México: Universidade Nacional Autónoma, 1983).

CAROCHI, Horacio; PAREDES, Ignácio de. Compendio del Arte de la Lengua Mexicana del Padre Horácio Carochi de la Compañia de Jesús - dispuesto con brevedad, claridad y propriedad por el Padre Ignácio de Paredes de la misma Compañia, y morador del colégio destinado solamente para indios, de San Gregorio de la Compañia de Jesús de México. [...] Reimpreso de la edición hecha en México, en la Imprenta de la Biblioteca Mexicana, el año de 1759. Puebla: Talleres de la Imprenta, Encuadernación y Rayado "El Escritório” Zaragoza 8, 1910.

CORTESÃO, Jaime. A expedição de Pedro Álvares Cabral e o descobrimento do Brasil. Lisboa: Imprensa Nacional Casa da Moeda, 1994.

FIGUEIRA, Pe. Luís. Arte de grammatica da lingua do Brasil. Nova publ. - Facs. da edição de 1687; Julio Platzmann (Hrsg.]. Leipzig: Teubner (Lisboa: Officina Patriarchal), 1878.

GÂNDAVO, Pêro de Magalhães de. Tratado da Terra E História do Brasil, 1576. (Org. por Leonardo Dantas Silva). Recife: Fundação Joaquim Nabuco, Eda. Massangana, 1995.

HERNÁNDEZ SACRISTÁN, Carlos. Categoría formal, categoría funcional y teoría de la translación en las primeras gramáticas del nahuatl. In: ZIMMERMANN, Klaus (Ed.). La descripción de las lenguas amerindias en la época colonial. Frankfurt/M.: Vervuert, 1997. p. 43-58. (Biblioteca Ibero-Americana, 63) 
HERNÁNDEZ SACRISTÁN, Carlos. Estrutura argumental y diátesis en nahuatl: consideraciones sobre una visión de mundo. In: THIELEMANN, Werner; WELKE, Klaus (Ed.). Valenztheorie - Einsichten und Ausblicke. Münster: Nodus, 2001. p. 143-155.

HERVÁS Y PANDURO, Lorenzo. Idea dell'universo, che continue la storia della vita dell'uomo, elementi cosmografici, viaggio estatico al mondo planetario, e storia della terra. Cesena: C. Biasini, 1778-1787. $20 \mathrm{v}$.

HERVÁS Y PANDURO, Lorenzo. Catalogo de las lenguas de las Naciones conocidas y numeración, división y clases de estas segun la diversidad de sus idiomas y dialetos. Madrid: Ranz, 1800-1805.

HUMBOLDT, Alexander von. Relation historique du voyage aux régions équinoxiales du Nouveau Continent (Voyage de Humboldt et Bonpland. Première partie. Relation historique). Paris: Schoell et all, 1814-1815. 3 v.

HUMBOLDT, Wilhelm von. Gesammelte Schriften, 17 Bde. Hrsg. v. Albert Leitzmann (1-15) u. Wilbelm Richter (16-17). Berlin: Königliche Preußische Akademie der Wissenschaften, 1903-1906.

HUMBOLDT, Wilhelm von. Wilhelm von Humboldt - Sein Leben und Wirken, dargestellt in Briefen, Tagebüchern und Dokumenten seiner Zeit. Ausgewäblt und zusammengestellt von Rudolf Freese. Berlin: Verlag der Nation, 1953.

HUMBOLDT, Wilhelm von. Ueber die Verschiedenheit des menschlichen Sprachbaues und ihren Einfluss auf die geistige Entwicklung des Menschengeschlechts. In: FLITNER, Andreas; GIEL, Klaus (Ed.). Wilhelm von Humboldt, Werke in fünf Bänden. Stuttgart: J.G. Cotta'sche Buchhandlung, 1963. V. 3, p. 368-756.

HUMBOLDT, Wilhelm von. Mexicanische Grammatik. 1866. In: RINGMACHER, Manfred Ringmacher. Paderborn: F. Schöningh, 1994.

KOERNER, E. F. Konrad. "Metalanguage" in linguistic historiography. In: KOERNER, E. F. Konrad (Ed.). Professing linguistic bistoriography. Amsterdam/ Philadelphia: John Benjamins, 1995. p. 27-46. (Studies in the History of the Language Sciences, 79)

LAUNEY, Michel. Une grammaire omniprédicative. Essai sur la morphosyntaxe du nabuatl classique. Paris: CNRS Éditions, 1994.

MOLINA, Alonso de. Vocabulario en lengua Mexicana y Castellana. México: Casa de Pedro Ocharte, 1571.

NEBRIJA, Antonio. Grammatica de la lengua castellana, 1492. (Editado por QUILIS, Antonio. Madrid: Editora Nacional, 1984). 
OLIVEIRA, Fernão de. Gramática da linguagem portuguesa. 1536. (Edição crítica, semidiplomática e anastática por TORRES, Amadeu; ASSUNÇÃO, Carlos. Lisboa: Fundação Calouste Gulbenkian, 2000.

OLMOS, Andrés de. Arte de aprender para lengua mexicana. Grammaire de la langue Nahuatl ou mexicaine, composée en 1547, par le franciscain Andrés de Olmos et publiée avec notes, éclaircissments, etc. par Rémi Siméon. Paris: Imprimerie Nationale, 1875.

QUILIS, Antonio. Grammatica de la Lengua Castellana de Antonio de Nebrija. Madrid: Centro de Estudios Ramón Areces, 1989.

RINCÓN, Antonio del. Arte Mexicana. México: Pedro Balli, 1595. [Facsimile , Guadalajara, 1967].

RINGMACHER, Manfred. El vocabulario náhuatl de Molina leído por Humboldt y Buschmann. In: ZIMMERMANN, Klaus (Ed.). La descripción de las lenguas amerindias en la época colonial. Frankfurt/M.: Vervuert, 1997. p. 75-112. (Biblioteca Ibero-Americana, 63)

RODRIGUES, Carmen Lúcia Reis. Os pronomes cliticos em Xipaya. In: GELNE, V Simpósio, 1998, Fortaleza, Ceará.

ROSA, Luciano Caetano da. Considerações em torno da Arte de Grammatica de Anchieta. In: CASTRO, Silvio; SIMÕES, Manuel G. (Ed.). La Scrittura e la VoceAtti del Convegno internazionale sui gesuiti José de Anchieta e António Vieira. Padova: CLEUP Editrice, 1998. p.155-177.

SMITH STARK, Thomas C. Rincón y Carochi: la tradición jesuítica de descripción del náhuatl. In: ZWARTJES, Otto (Ed.). Las gramáticas misioneras de tradición bispánica (siglos XVI-XVII). Amsterdam, Atlanta: Rodopi B.V., 2000. p. 29-71.

SOARES PEREIRA, Virgínia da Conceição. Em torno da Arte de Gramática de Anchieta. In: TAVARES DE PINHO, S. de; FERREIRA, Nazaré (Ed.). Actas do Congresso Internacional Anchieta em Coimbra - Colégio das Artes da Universidade (1498-1998). Coimbra: Universidade/Fundação Eng. António de Almeida, 2001. p. 1123-1147.

TAVARES DE PINHO, S. de; FERREIRA, N. (Ed.). Actas do Congresso Internacional Anchieta em Coimbra - Colégio das Artes da Universidade (1498-1998). Coimbra: Universidade/ Fundação Eng. António de Almeida, 2001. 3 v.

THIELEMANN, Werner. Wilhelm von Humboldt e a sua obra sobre a diversidade das línguas humanas. Investigações. Recife (Pernambuco).: [s/e], n. 9, p. 165203, 1999. 
ZIMMERMANN, Klaus (Ed.). La descripción de las lenguas amerindias en la época colonial. Frankfurt/ M.: Vervuert, 1997. (Biblioteca Ibero-Americana, 63) ZWARTJES, Otto (Ed.). Las gramáticas misioneras de tradición hispánica (siglos XVI - XVII). Amsterdam, Atlanta: Rodopi B.V., 2000. 